\title{
Occupational Asthma in a Cable Manufacturing Company
}

\author{
Mirsaeed Attarchi ${ }^{1}$; Faezeh Dehghan ${ }^{2}$; Taraneh Yazdanparast ${ }^{3}$; Saber Mohammadi ${ }^{1}$; \\ Mahdie Golchin ${ }^{1}$; Zargham Sadeghi ${ }^{4}$; Masoud Moafi ${ }^{1}$; Seyed Mohammad Seyed Mehdi ${ }^{3,}$ \\ ${ }^{1}$ Department of Occupational Medicine, School of Medicine, Tehran University of Medical Sciences, Tehran, IR Iran \\ ${ }^{2}$ Department of Occupational Medicine, School of Medicine, AJA University of Medical Sciences, Tehran, IR Iran \\ 3 Research Center of Chronic Respiratory Disease, National Research Institute of Tuberculosis and Lung Diseases, Shahid Beheshti University of Medical Sciences, Tehran, IR Iran \\ ${ }^{4}$ Research Center of Work and Environment, Petroleum Industry Health Organization (PIHO), Tehran, IR Iran \\ ${ }^{*}$ Corresponding Author: Seyed Mohammad Seyed Mehdi, Research Center of Chronic Respiratory Disease, National Research Institute of Tuberculosis and Lung Diseases, Shahid \\ Beheshti University of Medical Sciences, Tehran, IR Iran. Tel:+98-217123000, Fax:+98-2126109484, E-mail: Mseyedmehdi@nritld.ac.ir
}

Received: November 20, 2012; Revised: October 7, 2013; Accepted: August 31, 2014

\begin{abstract}
Background: During the past decade, incidence of asthma has increased, which might have been due to environmental exposures. Objectives: Considering the expansion of cable manufacturing industry in Iran, the present study was conducted to evaluate the prevalence of occupational asthma in a cable manufacturing company in Iran as well as its related factors.

Patients and Methods: This study was conducted on employees of a cable manufacturing company in Yazd, Iran, in 2012. The workers were divided into two groups of exposure (to toluene diisocyanate, polyvinyl chloride, polyethylene or polypropylene) and without exposure. Diagnosis of occupational asthma was made based on the subjects' medical history, spirometry and peak flowmetry, and its frequency was compared between the two groups.

Results: The overall prevalence of occupational asthma was 9.7\%. This rate was $13.8 \%$ in the exposed group. Logistic regression analysis showed that even after adjustment for confounding factors, a significant correlation existed between the frequency of occupational asthma and exposure to the produced dust particles $(\mathrm{P}<0.05)$. In addition, age, work experience, body mass index, cigarette smoking and shift work had significant correlations with the prevalence of occupational asthma $(\mathrm{P}<0.05)$.

Conclusions: Considering the high prevalence of occupational asthma among cable manufacturing company workers in Iran, this issue needs to be addressed immediately in addition to reduction of exposureamong subjects. Reduction in workshiftduration, implementation of tobacco control and cessation programs for the personnel, and performing spirometry tests and respiratory examinations in shorter periods may be among effective measures for reducing the incidence of occupational asthma in this industry.
\end{abstract}

Keywords:Asthma; Occupational Asthma; Occupational Exposure

\section{Background}

Asthma is a global problem with significant social burdens and health costs. This disease is common in all age groups and approximately involves $5-10 \%$ of the adult population (1). Asthma is prevalent in all areas of Iran and has been reported in about $10 \%$ of the Iranian population (2). The prevalence of asthma has increased during the recent years. It was estimated that more than 17.5 million people had asthma in the United States in 2009 (3). The financial burden of asthma is considerably high. In the USA alone, the annual cost of health care services for this disease is at least 12.7 billion dollars (4). During the past decade, the incidence of asthma has increased, which may be attributed to environmental exposures rather than genetic factors (5). Asthma is a major growing problem in working age adults with a negative effect on their working abilities (6). In the USA, 10 to 12 million days of absence from work occur annually as a result of asthma (7). Work-related asthma is among the most common occupational pulmonary diseases (8). Work-related asthma is the most common occupational airway disease among industrial countries (9). Researches have shown a high prevalence of occupational asthma among Iranian workers (10-15). Despite the considerable reduction in the incidence of most occupational pulmonary diseases especially pneumoconiosis due to implementation of appropriate primary preventive measures, prevalence of asthma is still increasing (16). Application of new materials in working environments without knowing their short-term and long-term effects is among the main reasons for the growing incidence of asthma (16). Based on the published data, American Thoracic Society has estimated that the cause of asthma in 15\% of adults is exposure to hazardous materials in working environments (17).

On the other hand, there are some diseases that are important due to their association with asthma. For instance, the prevalence of allergic rhinitis in various studies has been reported 5-65\% (18). Association of allergic rhinitis with occupational asthma has been reported as high as $92 \%$. Allergic rhinitis usually occurs prior to oc-

Copyright (C) 2014, Iranian Red Crescent Medical Journal; Published by Kowsar. This is an open-access article distributed under the terms of the Creative Commons Attribution-NonCommercial 4.0 International License (http://creativecommons.org/licenses/by-nc/4.0/) which permits copy and redistribute the material just in noncommercial usages, provided the original work is properly cited. 
Attarchi M et al.

cupational asthma (18). Workers of cable manufacturing companies are exposed to several chemical agents, the most important of which is toluene diisocyanate, copper, poly propylene, polyethylene, and polyvinyl chloride. Isocyanates (including toluene diisocyanate) are currently the most common cause of occupational asthma $(19,20)$. They can result in functional and inflammatory changes in respiratory system even at very low concentrations (like $1 \mathrm{ppb}$ ) (21). On the other hand, even after discontinuation of exposure, inflammation may remain in cases with diisocyanate-induced asthma (19). When polypropylene is heated, several low-molecular-weight vapors are produced (22). Previous studies have reported heated polypropylene-induced occupational asthma (22). In addition, in a study conducted by Eschenbacher et al. an association was observed between nylon flock work and distinctive interstitial lung disease. Additionally, a high percentage of nylon flock workers had respiratory diseases. By discontinuing the work and workplace exposure, a higher percentage of recovered subjects were observed among polypropylene-exposed workers compared with controls (23).

Polyethylene is widely used in shrink wrapping industries, for covering the cables and in pipe manufacturing companies (24). It has been reported that pyrolysis products of polyethylene and polyvinylchloride (PVC) can cause occupational asthma. PVC vapor can cause occupational asthma as well (24). Ng et al. in their study showed that workers with high cumulative PVC dust exposure had a lower $\mathrm{FEV}_{1}$ (Forced expiratory volume in one second) and FVC (Forced Vital Capacity) and prevalence of wheezing and chest tightness was significantly higher in the exposed group (25).

Polyethylene is among the causes of occupational asthma in workers in wrapping industries. Its association with asthma has also been reported in some other relevant industries such as cable and paint manufacturing companies (24). Gannon and colleagues reported a case of occupational asthma in a shrink wrap company, using a different plastic, polyethylene. This association was confirmed by specific bronchial provocation testing (24).

Several epidemiologic studies showed that application of PVC was associated with increased risk of asthma and allergy. In the study by $\mathrm{Ng}$ et al. it was revealed that respiratory complaints were significantly more prevalent in the morning after exposure to PVC compared with controls (25). Early diagnosis of occupational asthma is important, because in various studies it has been demonstrated that prognosis of occupational asthma is poorer than that of nonoccupational asthma (26). In addition, people with occupational asthma have a greater likelihood to encounter financial barriers than patients with nonoccupational asthma (26). Respiratory symptoms and airway hyper responsiveness to meth choline persist in subjects removed from exposure to toluene diisocyanate for more than 10 years (27). Furthermore, a more favorable prognosis was associated with a better lung func- tion and a lower degree of airway hyper responsiveness to meth choline at diagnosis (27).

\section{Objectives}

Considering the high number of cable manufacturing companies and expansion of this industry in Iran, the present study was conducted to evaluate the frequency of occupational asthma in a cable manufacturing company.

\section{Patients and Methods}

\subsection{Study Design and Population}

This cross-sectional study was conducted on workers of a cable manufacturing company in Yazd, Iran, in 2012. All the workers in production units who had exposure to toluene diisocyanate, PVC, polyethylene or polypropylene, were entered in the study as the exposed group. All other workers working in warehouse and packaging units of the company were considered as the unexposed group. All the workers were male. History of exposure to asthmogenic materials in their second job or previous occupation and history of respiratory diseases (like asthma and rhinitis) before employment in the understudy workers of the cable manufacturing company were considered as the exclusion criteria. For a 95\% confidence interval (CI), power of 0.5 and margin of error (d) no more than 0.07 , the sample size was estimated to be approximately 200. Eventually, 188 workers comprised the unexposed group and 356 comprised the exposed group.

A questionnaire, specifically designed for this study, was filled out for all the subjects. The respiratory questionnaire was designed according to the American Thoracic Society (ATS) standard questionnaire with a few changes and was filled out for all the understudy subjects (28).

The questionnaire included demographic characteristics, medical history, familial history, respiratory complaints (cough, sputum, dyspnea, wheezing, sneezing, rhinorrhea, nasal congestion, post-nasal discharge, eye and nose itching, etc.) inside or outside the work environment, duration of symptoms and their resolution by omitting work exposure, history of allergy and asthma and time of onset, medication intake, cigarette smoking, respiratory diseases and complaints before employment in the present occupation, a precise occupational history (type of occupation, risks, previous occupation, etc.) and shift work. After completion of the questionnaire, all the understudy subjects were clinically examined by two physicians with special attention to the respiratory system.

All the subjects provided a written informed consent before initiation of the study. They were informed that they are free to quit and leave the study whenever they wish. This study was approved by the Ethics Committee of the National Research Institute of Tuberculosis and Lung Diseases. The code and date of ethical approval was CRD 9136, 14 April 2012. 
Attarchi M et al.

\subsection{Environmental Measurement}

Environmental measurements were performed by the occupational health team of the company. Concentration of dust particles in the work environment was measured and the results showed that the mean concentration of respirable dust particles in the production unit and its total concentration were 6.03 (range: 4.01 to 9.13) and 16.21 (range: 21.20 to 12.36 ) $\mathrm{mg} / \mathrm{m}^{3}$, respectively. Workers in the exposed group were exposed to dust particle concentrations over the permissible exposure limit (29). The concentration of dust particles were negligible and below the permissible exposure limit in the warehouse and packaging units.

\subsection{Pulmonary Function Tests}

Pulmonary function tests (PFTs) were performed using a portable spirometer (Spirolab III, MIR Co, Italy) in the sitting position and with the use of a nasal clip according to the standards of American Thoracic Society (ATS) (30-32). For each subject, spirometry test was performed for a minimum of three times and the best value between the three was recorded. All the tests were performed by a trained physician between 9-11 AM. The following spirometric indices were used for reporting the study results:

1) Forced expiratory volume in one second $\left(\mathrm{FEV}_{1}\right)$

2) Forced vital capacity (FVC)

3) $\mathrm{FEV}_{1} / \mathrm{FVC}$

4) Forced expiratory flow between $25 \%$ and $75 \%$ of the FVC (FEF 25-75\%)

5) Peak expiratory flow (PEF)

6) Study subjects were divided into normal, obstructive, restrictive and mixed patterns based on spirometric findings (32).

All the measurements were expressed as the percentage of normal values and were adjusted for age and height. Spirometric tests of all the subjects who had respiratory signs or obstructive patterns in their simple spirometry tests were repeated 15-20 minutes after the inhalation of $400 \mu \mathrm{g}$ salbutamol spray; $12 \%$ or $200 \mathrm{~mL}$ increase in FEV1 or $20 \%$ increase in PEF was considered as significant or positive reversibility.

\subsection{Peak Flowmetry}

All the workers who had respiratory signs or symptoms or obstructive patterns in simple spirometry tests were trained for using peak flow meter and this test was performed for them. They were asked to perform it twice a day (at the beginning and at the end of each shift work) three times for one week and record the results (33). All the workers were evaluated for proper conduction of the test on day two. Of the three measured values at each time of testing, the greatest was recorded.

The calculated normal peak flow based on the worker's age, height, and weight was compared with the maximum peak flow taken at the beginning and the end of each shift work. Changes in peak flowmetry were calcu- lated for each worker. According to the ATS, a decrease of more than $20 \%$ was considered as positive (34).

\subsection{Outcomes Measurement}

In this study, occupational asthma was defined based on the criteria indicated by the American College of Chest Physicians (ACCP) (35).

1) Presence of a clinical compliant of asthma (coughing, wheezing, and dyspnea) that resolves by removal from work exposure.

2) Positive reversibility in spirometry test along with more than $20 \%$ change in the PEF value.

Rhinitis was diagnosed based on presence of sneezing, rhinorrhea, nasal congestion, postnasal discharge, and constant eye and nose itching, related to work (36).

Chest x-ray was obtained in all the subjects, for whom another diagnosis was proposed based on their medical history, clinical examination and performed tests. In suspicious cases, the chest x-ray diagnoses were confirmed by CT scan.

Shift of work was measured by asking the respondents to rate which of the following categories described their current work schedule: fixed day shift, fixed evening shift, or rotating shift. Fixed day shift was considered day work, and the other categories were considered shift work (37).

\subsection{Statistical Analysis}

SPSS version 11 software was used for data analysis. Percentage, frequency, mean and standard deviation were used for descriptive analysis. T-test was used for comparing the means of quantitative variables; whereas chisquare test was used for qualitative variables. Logistic regression analysis was used for precise evaluation of the correlation between occupational asthma and occupational exposure. In all the statistical tests, confidence interval (CI) was $95 \%$ and $\mathrm{P}<0.05$ was considered statistically significant.

\section{Results}

This study evaluated 544 personnel, working in production, packaging and warehouse units of a cable manufacturing company, of which 356 (65.4\%) worked in production units and comprised the exposed group and 188 (34.6\%) worked in warehouse and packaging units and comprised the unexposed group. The mean age of all the subjects was 38.75 years old (range: $23-61$ years). The mean work experience was 11.36 years (range: 1 to 23 years). The mean height was $174.30 \mathrm{~cm}$ (range: 158 to $197 \mathrm{~cm}$ ) and the mean weight was $78.40 \mathrm{~kg}$ (range: 52 to $101 \mathrm{~kg}$ ). A total of 104 subjects (19.1\%) were smokers and 159 (29.2\%) were shift workers. Table 1 compares the exposed and unexposed groups in terms of demographic characteristics. As observed in this table, the two groups had no significant differences in terms of mean age, work experience, mean height, mean weight, shift work, and cigarette consumption $(\mathrm{P}>0.1)$. In terms of respiratory complaints, 
98 subjects (27.5\%) in the exposed group and 34 (18.1\%) in the unexposed group had respiratory complaints and the frequency of respiratory complaints in the exposed group was significantly higher than the unexposed group $(\mathrm{P}=0.016, \mathrm{OR}=1.72,95 \% \mathrm{CI}=1.11-2.66)$. Table 2 compares the frequency of respiratory complaints between the two groups based on the type of respiratory complaint. As demonstrated in this table, all the respiratory complaints were significantly higher in the exposed group. Of all the subjects, 431 (79.2\%) had normal and 113 (20.8\%) had abnormal spirometric findings. In the unexposed group 22 (11.7\%) and in the exposed group 91 (25.6\%) subjects had abnormal spirometry results. The frequencies of abnormal pulmonary function tests were significantly higher in the exposed group $(\mathrm{P}<0.001, \mathrm{OR}=2.59,95 \% \mathrm{CI}=1.56)$. In the exposed group, 72 subjects (20.3\%) had obstructive and 19 (5.3\%) had restrictive patterns. In the unexposed group, 18 (9.5\%) had obstructive and 4 (2.2\%) had restrictive patterns. The mean values of spirometric indices were significantly higher in the exposed group $(\mathrm{P}=0.001)$ (Table 3$)$. Rhinitis was present in 48 subjects (8.8\%). Rhinitis was reported by 42 subjects in the exposure (11.8\%) and 6 (3.2\%) in the unexposed group. Therefore, its frequency was significantly higher among the exposed group $(\mathrm{P}<0.001$, $\mathrm{OR}=4.05$, $95 \% \mathrm{CI}=1.69-9.73)$. A total of 53 subjects (9.7\%) of all the understudy population had occupational asthma. Occupational asthma was diagnosed in 49 (13.8\%) subjects in the exposure and 4 (2.1\%) in the unexposed groups. Therefore, the frequency of occupational asthma was significantly higher in the exposed group $(\mathrm{P}<0.001, \mathrm{OR}=7.34,95 \% \mathrm{CI}$ $=2.60-20.67)$. The frequency of occupational asthma was $29.8 \%$ (31 subjects) in the smoker and 5.0\% (22 subjects) in the nonsmoker group. The frequency of occupational asthma was $17.6 \%$ (28 subjects) among shift workers and $6.5 \%$ (25 subjects) among non-shift workers. The frequency of occupational asthma was significantly greater among smokers and shift workers $(\mathrm{P}<0.001)$ (Table 4). Logistic regression analysis was used for more precise evaluation of the correlation between the frequency of occupational asthma and occupational respiratory exposures (Table 4). The results of this analysis showed that even after adjustment for confounding factors, there was a significant association between the frequency of occupational asthma and exposure to dust particles $(\mathrm{P}<0.05)$. In addition, age, work experience, body mass index (BMI), cigarette smoking and shift work were significantly associated with the frequency of occupational asthma $(\mathrm{P}<0.05)$.

\section{Discussion}

Work-related asthma is among the most common occupational diseases, which imposes high costs to patients, healthcare systems and insurance companies in Iran every year. Some industries such as bakery and steel industries have been studied for occupational asthma in Iran (38-40). Cable manufacturing is an industry in which workers are exposed to several asthmogens, the most import of which is toluene diisocyanate. In this study, we evaluated the overall effect of these agents in this industry on development of work-related asthma. In the present study, the frequency of work-related asthma was 9.7\%. The frequency of work-related asthma was $13.8 \%$ in the exposed and $2.1 \%$ in the unexposed groups, which was significantly higher in the exposed group. Even after adjustment for confounding factors, significant associations were detected between asthma frequency and occupational exposures (Table 4). Sigari et al. reported that asthma prevalence in bakery workers was 11.9\%, (40) and Mirmohammadi et al. reported that 3.9\% in steel industry workers (38).

Table 1. Comparison of Related Variables Between the Exposed and Unexposed Groups ${ }^{\text {a }}$

\begin{tabular}{|c|c|c|c|}
\hline Variable & $\begin{array}{c}\text { Exposed } \\
\text { Group }(n= \\
356)\end{array}$ & $\begin{array}{c}\text { Unexposed } \\
\text { Group }(\mathbf{n}= \\
188)\end{array}$ & P Value \\
\hline Age, y & $38.50 \pm 4.72$ & $39.23 \pm 5.41$ & 0.103 \\
\hline Duration of work, $y$ & $11.48 \pm 4.13$ & $11.11 \pm 5.80$ & 0.388 \\
\hline Body mass index, $\mathrm{kg} / \mathrm{m}^{2}$ & $25.53 \pm 2.80$ & $25.85 \pm 3.44$ & 0.116 \\
\hline Height, cm & $174.58 \pm 5.88$ & $173.82 \pm 5.30$ & 0.137 \\
\hline Weight, kg & $77.85 \pm 11.28$ & $79.45 \pm 10.51$ & 0.110 \\
\hline Smoking & $76(21.3)$ & $28(14.9)$ & 0.085 \\
\hline Shift work & $105(29.5)$ & $54(28.7)$ & 0.921 \\
\hline
\end{tabular}

a Values are present as Mean \pm SD and No. (\%).

Table 2. Prevalence of Respiratory Symptoms Among Exposed and Unexposed Groups ${ }^{\text {a }}$

\begin{tabular}{lccc}
\hline Symptom & $\begin{array}{c}\text { Exposed Group } \\
(\mathbf{n = 3 5 6 )}\end{array}$ & $\begin{array}{c}\text { Unexposed } \\
\text { Group (n=188) }\end{array}$ & PValue \\
\hline Dyspnea & $68(19.1)$ & $11(5.8)$ & $<0.001$ \\
$\begin{array}{l}\text { Shortness of } \\
\text { breath at work }\end{array}$ & $50(14.0)$ & $7(3.7)$ & $<0.001$ \\
Cough & $46(12.9)$ & $12(9.0)$ & 0.023 \\
Wheeze & $44(12.3)$ & $10(5.3)$ & $<0.001$ \\
Sputum & $43(12.0)$ & $16(8.5)$ & 0.017 \\
\hline
\end{tabular}

${ }^{\mathrm{a}}$ Values are present as No.(\%).

Table 3. Mean Values of Spirometric Parameters in Exposed and Unexposed Groups a,b

\begin{tabular}{lccc}
\hline Parameter & $\begin{array}{c}\text { Exposed } \\
\text { Workers }\end{array}$ & $\begin{array}{c}\text { Unexposed } \\
\text { Workers }\end{array}$ & P Value \\
\hline FEV $_{\mathbf{1}}$ & $74.52 \pm 9.55$ & $87.98 \pm 13.74$ & $<0.001$ \\
$\mathbf{F V C}$ & $77.32 \pm 8.15$ & $89.05 \pm 12.13$ & $<0.001$ \\
FEV $_{\mathbf{1}} / \mathbf{F V C}$ & $79.65 \pm 6.65$ & $82.55 \pm 5.19$ & $<0.001$ \\
FEF $_{\mathbf{2 5 - 7 5} \%}$ & $72.30 \pm 6.31$ & $87.31 \pm 19.98$ & $<0.001$ \\
PEF & $76.99 \pm 7.36$ & $85.91 \pm 14.25$ & $<0.001$ \\
\hline
\end{tabular}

a Abbreviations: FCV, forced vital capacity; FEF, forced expiratory flow;

FEV, forced expiratory volume; PEF, peak expiratory flow.

$\mathrm{b}$ All the Values are present as Mean \pm SD. 
Attarchi M et al.

\begin{tabular}{|c|c|c|c|c|c|c|}
\hline Variables & Crude OR & 95\% CI & P Value & Adjusted OR & 95\% CI & P Value \\
\hline \multicolumn{7}{|l|}{ Exposure Groups } \\
\hline Unexposed $(\mathrm{n}=188)$ & 1 & - & - & 1 & - & - \\
\hline Exposed $(\mathrm{n}=356)$ & 7.34 & $2.60-20.67$ & $<0.01$ & 5.68 & $1.41-13.87$ & 0.029 \\
\hline \multicolumn{7}{|l|}{ Age, y } \\
\hline$\leq 38(\mathrm{n}=282)$ & 1 & - & - & 1 & - & - \\
\hline$>38(\mathrm{n}=262)$ & 4.75 & $1.88-12.36$ & $<0.01$ & 3.84 & $1.69-8.71$ & 0.001 \\
\hline \multicolumn{7}{|l|}{ Work experience, y } \\
\hline$\leq 11(\mathrm{n}=268)$ & 1 & - & - & 1 & - & - \\
\hline$>11(\mathrm{n}=276)$ & 4.01 & $1.62-8.41$ & $<0.01$ & 2.32 & $1.11-4.87$ & 0.025 \\
\hline \multicolumn{7}{|l|}{ BMI, $\mathrm{kg} / \mathrm{m}^{2}$} \\
\hline$<25.7(\mathrm{n}=260)$ & 1 & - & - & 1 & - & - \\
\hline$\geq 25.7(n=284)$ & 2.76 & $1.13-4.96$ & $<0.05$ & 2.01 & $1.05-3.85$ & 0.035 \\
\hline \multicolumn{7}{|l|}{ Smoking pack, y } \\
\hline Non-smoker $(\mathrm{n}=440)$ & 1 & - & - & 1 & - & - \\
\hline$\leq 5(\mathrm{n}=54)$ & 5.37 & $1.88-12.28$ & $<0.01$ & 2.46 & $1.09-7.43$ & 0.033 \\
\hline$>5(n=50)$ & 8.06 & $4.42-14.70$ & $<0.01$ & 3.89 & $1.56-9.71$ & 0.004 \\
\hline \multicolumn{7}{|l|}{ Shift work } \\
\hline No $(n=385)$ & 1 & - & - & 1 & - & - \\
\hline Yes $(n=159)$ & 3.07 & $1.72-5.47$ & $<0.01$ & 4.57 & $1.73-8.94$ & $<0.001$ \\
\hline
\end{tabular}

a Abbreviations: BMI, body mass index; CI, confidence interval; OR, odds ratio.

As observed in Table 2, the frequencies of all respiratory complaints were significantly different between the two groups $(\mathrm{P}<0.05)$ and the overall frequency of respiratory complaints was $27.5 \%$ in the exposed group.

As demonstrated by the results of logistic regression analysis (Table 4), shift work, cigarette smoking of more than five packs/year, BMI greater than $25.7 \mathrm{~kg} / \mathrm{m}^{2}$, work experience more than 11 years, age older than 38 years and occupational exposure had significant correlations with work-related asthma.

In Ghasemkhani et al. study similar to our study, the prevalence of symptoms increased by increased work experience (41). Uddenfeldt et al. (42) showed that cigarette smoking was correlated with asthma. Such relationship was observed in our study as well. Previous studies demonstrated that airway narrowing or smoking were associated with greater deposition of small particles (less than $1 \mu \mathrm{m})(43)$. This finding can somehow justify the higher prevalence of asthma among smokers. Several studies similar to ours showed that higher BMI was correlated with development of asthma $(42,44)$. In obese individuals, mechanical compression of thorax results in decreased tidal volume and lower stretching of bronchial muscles, which can result in increased airway responsiveness (44). On the other hand, visceral fat may induce preinflammatory mediators like IL6, which can cause subepithelial fibrosis and airway remodeling in animal models (45). Furthermore, even being overweight within the normal weight range can be related to asthma (46).
Allergic rhinitis is associated with work-related asthma in up to $92 \%$ of cases and it is considered a predisposing factor for asthma (18). In the present study, 53 subjects (from both the exposed and unexposed groups) had work-related asthma, of which 48 (in both groups) had rhinitis as well (90.5\% of cases).

The correlation of exposure to PVC and asthma has been demonstrated in various epidemiologic studies. Markowitz (47) showed that in fire fighters exposed to burning PVC there was an increased risk of asthma-related signs and symptoms. Jaakkola et al. showed that exposure to PVC present in interior surface materials was associated with risk of asthma (48). Phthalates as plasticizers are among the important components of PVCs and play a role in development of work-related asthma (49). Exposure to methylene diphenyl diisocyanate, hexamethyl diisocyanate and toluene 2, 4 diisocyanate can cause allergic reactions similar to type I allergic asthma (50). In our study, exposure to toluene diisocyanate and PVC in the forms of dust and fume was reported in the exposed group, which was higher than the permissible exposure limit. It seems that the main cause of work-related asthma in our study was exposure to the two aforementioned compounds.

Two approaches were considered in previous studies conducted on work-related asthma. Some studies evaluated one asthmogen in different industries. Some others concentrated on a specific industry rather than focusing on a specific compound $(41,51,52)$. However, none of them evaluated cable manufacturing industry. In the 
present study, we chose the second approach because the cumulative overall effect of these substances can be totally different than the individual effect of each one of them.

In the current study, the incidence of work-related asthma in the unexposed group was $2.1 \%$, which might be due to exposure of these subjects to small amounts of the understudy materials in nonproduction units. On the other hand, due to the health worker effect, the frequency of work-related asthma may have been underestimated.

The weakness points of the present study were as follows:

This was a cross-sectional study and had limitations.

Due to some technical limitations, personal sampling as a complementary method for area sampling was not performed.

Other studies showed that higher physical activity increased the overall inhalation of dust particles (43). In the present study, workers in the exposed group had greater physical activity because of the nature of their job compared with the unexposed group, but precise measurement and comparison of the rate of physical activity between the two groups was not performed. However, considering the type of work performed by the first group which was not physically demanding, we do not assume that this issue had a significant impact on our findings.

Since this was a cross-sectional study, we could not conclude a cause and effect relationship. On the other hand, the prevalence of asthma in our study might have been underestimated due to the healthy worker effect. This study was the first in Iran to evaluate occupational asthma in cable manufacturing industry.

In conclusion, the present study results showed that occupational respiratory exposures in this industry in Iran were higher than the permissible exposure limit. Frequency of work-related asthma was 9.7\% among all the study subjects and $13.8 \%$ in the exposed group. Considering the high prevalence of work-related asthma in workers of cable manufacturing industry in Iran, it is necessary to immediately address this issue. Decreasing the occupational exposures is the main measure for reducing the incidence of work-related asthma in this industry. Reduction in work shift duration, implementation of tobacco control and cessation programs for personnel and performing spirometry tests and respiratory examinations in shorter periods may be among effective measures for reducing the incidence of occupational asthma in this industry.

\section{Funding/Support}

This study was sponsored by the National Research Institute of Tuberculosis and Lung Diseases (NRITLD), Iran.

\section{References}

1. Hendrick DJ. Recognition and surveillance of occupational asthma: a preventable illness with missed opportunities. Br Med Bull. 2010;95:175-92.
2. Pourabedian S, Barkhordari A, Habibi E, Rismanchiyan M, Zare M Effect of 1,6-hexamethylene diisocyanate exposure on peak flowmetry in automobile paint shop workers in Iran. Arh Hig Rada Toksikol. 2010;61(2):183-9.

3. Fakhouri TH, National Center for Health Statistics . Prevalence of obesity among older adults in the United States, 2007-2010: Citeseer; 2012.

4. Weiss KB, Sullivan SD. The health economics of asthma and rhinitis. I. Assessing the economic impact. J Allergy Clin Immunol. 2001;107(1):3-8.

5. Crapo JD, Broaddus VC, Brody AR, Malindzak G, Samet J, Wright JR, et al. Workshop on lung disease and the environment: where do we go from here? Am J Respir Crit Care Med. 2003;168(2):250-4

6. Lindstrom I, Pallasaho P, Luukkonen R, Suojalehto H, Karjalainen J, Lauerma A, et al. Reduced work ability in middle-aged men with asthma from youth-a 20-year follow-up. Respir Med. 2011;105(6):950-5.

7. CDC National Center for Health Statistics . Asthma prevalence. healthcare mortal. 2005.

8. Smith AM, Bernstein DI. Management of work-related asthma. Allergy Clin Immunol. 2009;123(3):551-7.

9. Broding HC, Frank P, Hoffmeyer F, Bunger J. Course of occupational asthma depending on the duration of workplace exposure to allergens - a retrospective cohort study in bakers and farmers. Ann Agric Environ Med. 2011;18(1):35-40.

10. Boskabady MH, Karimiani EG, Vostacolaei HA. Respiratory symptoms and pulmonary function changes among carpet weavers in Iran. Int J Occup Environ Health. 2007;13(4):369-75.

11. Boskabady MH, Rezaiyan MK, Navabi I, Shafiei S, Shafiei S. Workrelated respiratory symptoms and pulmonary function tests in Iranian printers. Saudi Med J. 2009;30(9):1170-5.

12. Boskabady MH, Rezaiyan MK, Navabi I, Shafiei S, Arab SS. Workrelated respiratory symptoms and pulmonary function tests in northeast iranian (the city of Mashhad) carpenters. Clinics (Sao Paulo). 2010;65(10):1003-7.

13. Boskabady MH, Taheri E, Ahmadi S, Ebrahimi K, Soudaneh M, Mohammadi F, et al. Pulmonary function tests and work-related respiratory and allergic symptoms in Iranian bakers. Iran J Allergy Asthma Immunol. 2009;8(2):107-10.

14. Hashemi N, Boskabady MH, Nazari A. Occupational exposures and obstructive lung disease: a case-control study in hairdressers. Respir Care. 2010;55(7):895-900.

15. Khazdair MR, Boskabady MH, Afshari R, Dadpour B, Behforouz A, Javidi $\mathrm{M}$, et al. Respiratory symptoms and pulmonary function testes in lead exposed workers. Iran Red Crescent Med J. 2012;14(11):737-42.

16. Tutar N, Demir R, Buyukoglan H, Oymak FS, Gulmez I, Kanbay A The prevalence of occupational asthma among denim bleachery workers in Kayseri. Tuberk Toraks. 2011;59(3):227-35.

17. Balmes J, Becklake M, Blanc P, Henneberger P, Kreiss K, Mapp C, et al. American Thoracic Society Statement: Occupational contribution to the burden of airway disease. Am J Respir Crit Care Med 2003;167(5):787-97.

18. Johnson VJ, Yucesoy B, Reynolds JS, Fluharty K, Wang W, Richardson $\mathrm{D}$, et al. Inhalation of toluene diisocyanate vapor induces allergic rhinitis in mice. J Immunol. 2007;179(3):1864-71.

19. Piirila PL, Meuronen A, Majuri ML, Luukkonen R, Mantyla T, Wolff HJ, et al. Inflammation and functional outcome in diisocyanate-induced asthma after cessation of exposure. Allergy. 2008;63(5):583-91.

20. Palikhe NS, Kim JH, Park HS. Biomarkers predicting isocyanateinduced asthma. Allergy Asthma Immunol Res. 2011;3(1):21-6.

21. Lemiere C, Romeo P, Chaboillez S, Tremblay C, Malo JL. Airway inflammation and functional changes after exposure to different concentrations of isocyanates. J Allergy Clin Immunol. 2002;110(4):641-6.

22. Malo JL, Cartier A, Pineault L, Dugas M, Desjardins A. Occupational asthma due to heated polypropylene. Eur Respir J.1994;7(2):415-7.

23. Eschenbacher WL, Kreiss K, Lougheed MD, Pransky GS, Day B, Castellan RM. Nylon flock-associated interstitial lung disease. Am J Respir Crit Care Med.1999;159(6):2003-8.

24. Gannon PF, Burge PS, Benfield GF. Occupational asthma due to polyethylene shrink wrapping (paper wrapper's asthma). Thorax 
Attarchi M et al.

1992;47(9):759.

25. Ng TP, Lee HS, Low YM, Phoon WH, Ng YL. Pulmonary effects of polyvinyl chloride dust exposure on compounding workers. Scand J Work Environ Health. 1991;17(1):53-9.

26. Knoeller GE, Mazurek JM, Moorman JE. Work-related asthma, financial barriers to asthma care, and adverse asthma outcomes: asthma call-back survey, 37 states and District of Columbia, 2006 to 2008. Med Care. 2011;49(12):1097-104.

27. Padoan M, Pozzato V, Simoni M, Zedda L, Milan G, Bononi I, et al. Long-term follow-up of toluene diisocyanate-induced asthma. EurRespir J. 2003;21(4):637-40.

28. Ferris BG. Epidemiology Standardization Project (American Thoracic Society). Am Rev Respir Dis. 1978;118(6 Pt 2):1-120.

29. Dasch J, D'Arcy J. Physical and chemical characterization of airborne particles from welding operations in automotive plants. $J$ Occup Envi Hygien. 2008;5(7):444-54.

30. Miller MR, Crapo R, Hankinson J, Brusasco V, Burgos F, Casaburi $\mathrm{R}$, et al. General considerations for lung function testing. Eur Respir J. 2005;26(1):153-61.

31. Miller MR, Hankinson J, Brusasco V, Burgos F, Casaburi R, Coates A, et al. Standardisation of spirometry. Eur Respir J. 2005;26(2):319-38.

32. Pellegrino R, Viegi G, Brusasco V, Crapo RO, Burgos F, Casaburi R, et al. Interpretative strategies for lung function tests. Eur Respir J. 2005;26(5):948-68.

33. Pourabedian S, Barkhordari A, Habibi E, Rismanchiyan M, Zare M. Effect of 1, 6-Hexamethylene Diisocyanate Exposure on Peak Flowmetry in Automobile Paint Shop Workers in Iran. Arch Indust Hygien Toxicol. 2010;61(2):183-9.

34. Standardization of Spirometry, 1994 Update. American Thoracic Society. Am J Respir Crit Care Med. 1995;152(3):1107-36.

35. Tarlo SM, Balmes J, Balkissoon R, Beach J, Beckett W, Bernstein D, et al. Diagnosis and management of work-related asthma: American College Of Chest Physicians Consensus Statement. Chest. 2008;134(3 Suppl):1S-41S.

36. Brisman J, Jarvholm B, Lillienberg L. Exposure-response relations for self reported asthma and rhinitis in bakers. Occup Environ Med. 2000;57(5):335-40.

37. Kivimaki M, Virtanen M, Elovainio M, Vaananen A, KeltikangasJarvinen L, Vahtera J. Prevalent cardiovascular disease, risk factors and selection out of shift work. Scand J Work Environ Health. 2006;32(3):204-8.

38. Mirmohammadi SJ, Mehrparvar AH, Gharavi M, Fathi F. A Comparison between Venables Standardized Respiratory Questionnaire and Pre-Shift Spirometry in Screening of Occupational
Asthma in a Steel Industry. Int J Occ Environ Med. 2010;1(4):191-197.

39. Ehteshami-Afshar A, Zahmatkesh MM. Prevalence of baker's asthma in Tehran, Iran. Arch Iranian Med. 2003;6(4):301-3.

40. Sigari N, Rahimi E, Yazdanpanah K, Sharifian A. Prevalence of asthma and rhinitis in bakery workers in the city of Sanandaj, Iran. Iran J Allergy Asthma Immunol. 2007;6(4):215-8.

41. Ghasemkhani M, Kumashiro M, Rezaei M, Anvari AR, Mazloumi A, Sadeghipour HR. Prevalence of respiratory symptoms among workers in industries of south Tehran, Iran. Ind Health. 2006;44(2):218-24.

42. Uddenfeldt M, Janson C, Lampa E, Leander M, Norback D, Larsson L, et al. High BMI is related to higher incidence of asthma, while a fish and fruit diet is related to a lower- Results from a long-term follow-up study of three age groups in Sweden. Respir Med. 2010;104(7):972-80.

43. Tarlo SM, Purdham J. Air sampling in occupational asthma. J Allergy Clin Immunol. 2002;109(4):603-5.

44. Kronander UN, Falkenberg M, Zetterstrom O. Prevalence and incidence of asthma related to waist circumference and BMI in a Swedish community sample. Respir Med. 2004;98(11):1108-16.

45. Jousilahti P, Salomaa V, Hakala K, Rasi V, Vahtera E, Palosuo T. The association of sensitive systemic inflammation markers with bronchial asthma. Ann Allergy Asthma Immunol. 2002;89(4):381-5.

46. Litonjua AA, Sparrow D, Celedon JC, DeMolles D, Weiss ST. Association of body mass index with the development of methacholine airway hyperresponsiveness in men: the Normative Aging Study. Thorax. 2002;57(7):581-5.

47. Markowitz JS. Self-reported short- and long-term respiratory effects among PVC-exposed firefighters. Arch Environ Health. 1989;44(1):30-3.

48. Jaakkola JJ, Ieromnimon A, Jaakkola MS. Interior surface materials and asthma in adults: a population-based incident case-control study. Am JEpidemiol. 2006;164(8):742-9.

49. Tsai MJ, Kuo PL, Ko YC. The association between phthalate exposure and asthma. Kaohsiung J Med Sci. 2012;28(7 Suppl):S28-36.

50. Wisnewski AV, Jones M. Pro/Con debate: Is occupational asthma induced by isocyanates an immunoglobulin E-mediated disease? Clin Exp Allergy. 2010;40(8):1155-62.

51. Shahzad K, Akhtar S, Mahmud S. Prevalence and determinants of asthma in adult male leather tannery workers in Karachi, Pakistan: a cross sectional study. BMC Public Health. 2006;6:292.

52. Keen C, Coldwell M, McNally K, Baldwin P, McAlinden J, Cocker J. A follow up study of occupational exposure to 4,4'-methylenebis(2-chloroaniline) (MbOCA) and isocyanates in polyurethane manufacture in the UK. Toxicol Lett. 2012;213(1):3-8. 